\title{
Inflamed skin lesions along the course of a nerve as patient self-help proxy indicator of nerve abnormalities in leprosy
}

\author{
M. F. Balagon ${ }^{\text {a }}$, A. M. Maghanoy ${ }^{\text {a }}$, F. O. Roferos ${ }^{\mathrm{a}} \&$ \\ P. R. Saunderson ${ }^{b}$ \\ ${ }^{a}$ Leonard Wood Memorial Center for Leprosy Research, Cebu, Philippines \\ bAmerican Leprosy Missions, Greenville, South Carolina, USA
}

Submitted 13 June 2021; Accepted 27 October 2021

\begin{abstract}
Summary
Objectives This study sought to determine the acceptability and utility of a selfassessment tool using inflamed skin lesions as proxy indicator of nerve abnormalities; and if nerve proximity to these skin lesions increases the risk of nerve abnormality and deformity in leprosy.

Methods A cohort of 200 Filipino patients were monitored before and during reaction. Using a self-assessment tool, skin lesions were independently scored by the patient and a clinician, while the nerves were assessed by a clinical staff. Skin lesions and nerves were scored on a $0-15$ severity scale; and nerves were noted as near or distant from the skin lesion. Skin lesions with type-1 or type-2 reactions were included.

Results A total of 314 inflamed skin lesions matched with the same number of nerves near and distant from skin lesions were studied. There was no significant difference $(P=0.1771)$ in skin lesion scores independently determined by the patient and the clinician. Mean skin lesion score was 2 in the absence of a reaction; and 5 at the peak of a reaction. Nerve scores remained low in the absence of a reaction, and when a reaction occurred in the skin lesion distant from the nerve. However, nerve scores were significantly higher when a skin lesion near the nerve became inflamed $(0.24$ vs $1.03 ; P<0.0001)$. Among these skin lesions, $15 \%$ had nerve findings before the skin reaction; $32 \%$ had both nerve and skin findings, while 53\% had skin reaction without nerve findings. At the peak of a reaction, seven new episodes of visible disability were recorded with skin lesion and nerve scores $\geq 3$; and all nerves involved were located near inflamed skin lesions. No deformity was associated with nerves distant from inflamed skin lesions. Ninety-five percent $(95 \%)$ of patients considered the tool highly acceptable, important and beneficial.

Conclusion and recommendation This study demonstrates the acceptability and utility of a self-assessment tool using inflamed skin lesions as proxy indicator of nerve abnormality; and that with adequate training,patients can reliably be delegated
\end{abstract}

Correspondence to: M. F. Balagon, Leonard Wood Memorial Center for Leprosy Research, Cebu-6000, Philippines (e-mail: marivicbalagon_20thilc@yahoo.com) 
to monitor their own skin lesions. This study also demonstrates the higher risk of deformity and abnormality among nerves near inflamed skin lesions.

Keywords: Self-assessment, nerve involvement, telephone helpline

\section{Introduction}

Leprosy is a disease manifested by the appearance of skin lesions with or without nerve findings. Skin lesions have a variable clinical course, depending on various factors such as response to treatment and lepra reaction, a common complication of leprosy which is largely dependent on the host's immunologic response. ${ }^{1-3}$ Lepra reactions are an immunologic phenomenon characterized by the appearance of signs and symptoms of inflammation which occur in over half of leprosy patients. ${ }^{1-4}$ Clinically, they are manifested by tenderness, erythema and elevation of existing lesions (type 1) or appearance of crops of painful nodules (type 2). ${ }^{1-3}$ These lesions may or may not be accompanied by nerve findings. Reactions often cause symptoms that compel the patient to seek medical attention. ${ }^{1}$ However, there seems to be a knowledge gap on how soon patients seek medical attention when lepra reaction occurs.

Since reactions put the patient at risk of nerve damage and deformities, it is important to recognize and treat reactions promptly since early recognition and adequate medical treatment of impending or early nerve damage may result in full restoration of nerve function. ${ }^{1,5-7}$ Unfortunately, many leprosy patients cannot afford regular clinic visits due to work, limited resources and/or lack of awareness of manifestations and likely complications of lepra reaction. It is therefore important to identify a simple and readily visible proxy indicator that will allow patients to conduct home-based self-monitoring to detect early signs of nerve abnormalities resulting in timely referral and treatment before deformities set in. One possible indicator is the presence of an inflamed skin lesion near or along the course of a nerve. For example, the presence of an inflamed skin lesion along the medial aspect of the right upper extremity could mean that the right ulnar nerve underneath might be at risk of functional impairment which, if not promptly treated, could lead to nerve damage and hand deformity.

An earlier study conducted in the same facility (the Leonard Wood Memorial Center for Leprosy Research in Cebu, Philippines) demonstrated that lagophthalmos was the most significant finding in ocular leprosy; and that notably 6 of 7 lagophthalmos cases occurred among a subset of patients with facial patches, suggesting that presence of facial patches alone denote a high-risk population. ${ }^{4}$ However, even if earlier studies demonstrate that reactions put the patient at risk of nerve damage and deformities, ${ }^{1,4,5}$ there remains a knowledge gap on the role of nerve proximity to an inflamed lesion as a risk factor for nerve abnormalities and deformities in leprosy.

This study aimed to determine the feasibility and acceptability of a simple lesion assessment tool that would empower patients to evaluate their own inflamed skin lesions as a proxy indicator of incipient nerve damage. We believe that if patients were taught to identify inflamed lesions, prompt referral and treatment would improve clinical outcomes, preventing deformity.

Another goal was to compare the findings of nerves located near vs nerves distant from an inflamed lesion to determine if nerve proximity to an inflamed lesion increases the risk of abnormalities and deformities in leprosy. 


\section{Materials and methods}

This prospective, observational cohort study was conducted in 2017-2020 at the Cebu Skin Clinic, a well-established leprosy treatment facility of the Leonard Wood Memorial Center for Leprosy Research (LWM) in Cebu, one of the most leprosy endemic areas in the Philippines. $^{8,9}$

This study observed skin lesions and peripheral nerves before and during reaction among newly diagnosed leprosy patients. Skin lesions were considered 'near' if they were located along the course of a nerve; and 'distant' if located at the opposite side or away from the course of a nerve. Skin lesions beyond $2 \mathrm{~cm}$ from the course of a nerve were considered distant. For instance, if a skin lesion were located at the medial aspect of the right arm and runs along the course of the right ulnar nerve, the right ulnar nerve was considered 'near' while the left ulnar nerve or any nerve $>2 \mathrm{~cm}$ away from the skin lesion was considered 'distant'.

Patients were sequentially enrolled in accordance with their date of diagnosis and satisfaction of inclusion criteria. Newly detected multibacillary (MB) and paucibacillary (PB) patients $\geq 10$ years old who consented for a long-term follow-up were recruited. Patients with $>5$ leprosy skin lesions and/ or positive skin smears regardless of lesion count were classified as MB; while patients with 1-5 smear negative skin lesions were classified as PB. Only patients without pre-existing signs of reaction were recruited to allow proper assessment of the timing of skin reactions and neuritis or nerve damage. Upon enrolment, dermatologic, neurologic and bacteriologic examination were conducted to provide full and thorough documentation of the disease. Patients were treated with WHO-MDT and monitoring was done monthly. Monitoring focused on skin lesion and nerve findings before and during reaction. In particular, skin lesion and nerve scores before reaction and at peak of reaction were analyzed and compared. The clinical score of a skin lesion during its non-inflammatory state was used as the baseline score. Visible deformities or grade 2 disabilities (G2Ds) were also recorded.

At monthly intervals, assessment and scoring of skin lesions were independently done by the patient and the clinician, while nerve evaluation was independently done by another staff. To avoid bias, blinding of findings was maintained between evaluators; and data management and correlation was done by a third party not directly involved in data collection.

Skin lesion assessment was regularly done using a simple lesion assessment tool, the Skin Lesion Severity Index (LSI scores; see Appendix A) using size, color, tenderness, swelling and ulceration as parameters. Depending on the severity of manifestations, each of the five parameters was scored 0-3 for a total score of 0-15. Nerves were also assessed using a similar five-point parameter: sensory, motor, enlargement, tenderness, and pain (see Appendix A). The more severe the findings, the higher the scores. The tool was translated into a simple layman's local dialect and patients were trained how to use the tool prior to study participation. In addition to LSI scores, the clinician also performed global assessment on lesion severity classified as mild, moderate or severe. Sensory evaluation was done using Semmes-Weinstein graded monofilaments. In this study, six peripheral nerves were included-facial, ulnar, radial, median, common peroneal and posterior tibial nerves.

Skin lesions with type-1 or type- 2 reactions were included. Since reactions could occur anytime, the use of a mobile phone exclusively dedicated as 'patient helpline' was enhanced for offsite referrals and consultations once signs of reaction were noted between visits. Supplemental to their regular clinic visits, patients who noted appearance of painful skin lumps/ nodules or increasing erythema and swelling of lesions were instructed to notify and visit the clinic for proper evaluation. 
Using a questionnaire in a layman's local dialect, a survey of patient's satisfaction of the self-monitoring tool was conducted at the start and upon completion of the study.

\section{The clinical tools}

The Skin Lesion Severity Index (LSI) is the outcome of consultative discussions with patients and field workers who expressed the need for a simple monitoring tool to alert them of any nerve abnormality requiring prompt referral and medical attention. Since they find nerve function assessment (NFA) difficult to interpret and perform at home and field settings, the need for a readily visible proxy monitor for nerve abnormalities was recognized. Consequently, the potential utility of an inflamed skin lesion along the course of a nerve as proxy monitor was considered. In consultation with clinical experts, the LSI was developed.

The LSI uses 5 parameters - size, color, swelling, tenderness, and the presence of skin breaks or ulceration. Each parameter was scored 0,1, 2 and 3 for normal, mild, moderate, severe manifestations. Scores were added together for a total of 0-15 (see Appendix A). Instead of lesion number, skin lesion size was used because small skin lesions have the tendency to coalesce during reaction (particularly type 1) so that one big skin lesion in one patient might be equivalent to multiple skin lesions in another patient. If there were multiple inflamed skin lesions along the course of a nerve, the combined size of skin lesions was approximated and scored.

The Nerve Severity Index (NSI) used size, tenderness, pain, motor and sensory function as parameters. Each parameter was scored 0,1, 2 and 3 respectively. The scores were added for a total of $0-15$. NSI is a simplified nerve function assessment (NFA) supplemented with severity scores to correlate with lesion scores. Nerve and skin lesion scores were correlated to determine if skin findings would proportionately reflect nerve findings.

The severity scales were reviewed by 3 committees-Leprosy Research Initiative (LRI) Steering Committee; LRI Independent Reviewers; and LWM's-IERB (Institutional Ethical \& Regulatory Board) embodied by senior medical experts and regulators; and persons with leprosy.

These clinical tools have not been used previously. However, our many years of experience and observation of the high concordance between skin and nerve findings during reaction, along with the growing need for patient inclusion and empowerment through self-monitoring, served as our springboard in developing the tools and in pursuing this feasibility and acceptability study among our patients.

\section{EVALUATION OF INFLAMED SKIN LESIONS}

Inflamed skin lesions with type-1 or type- 2 reactions were included. Regardless of morphology and reaction type, all skin lesions along the course of a nerve were evaluated and scaled. However, patients were only required to identify and scale skin lesions without classifying its morphologic presentation and reaction type. For further reference however, severity scaling and reaction type classification were independently performed by the clinician during clinic visits.

\section{TREATING REACTIONS}

Patients showing signs of reaction were managed using conventional treatment such as prednisolone and clofazimine. Treatment for reactions was based on clinical experience and real time assessment of each patient. Treatment was prednisolone at $0.5-1 \mathrm{mg} / \mathrm{kg} / \mathrm{day}$, tapered 
at increments of $5 \mathrm{mg}$ every 2 weeks depending on the patient's clinical response to current doses. For ENL, because thalidomide is not available in the Philippines, the same prednisolone regimen was given. Clofazimine was added for severe and debilitating reactions. The dose started at 200-300 mg/day tapered at increments of $50 \mathrm{mg}$ every 2-4 weeks depending on clinical response to current doses.

To reduce the likelihood of masking a possible neuritis, skin reactions without nerve impairment were not treated with steroids unless lesions worsened by at least $20 \%$ resulting in personal or social dysfunction; or if lesions were accompanied by nerve or systemic signs and symptoms beyond one week of supportive medication. However, severe neuritis with or without skin reaction was immediately treated with steroids. In all instances, steroids were only initiated after full dermatologic and neurologic assessment were performed and recorded.

Likewise, a survey questionnaire on patient's perception and acceptability of the selfassessment tool was conducted before and after study completion.

\section{PATIENTS' TRAINING}

Patients' training activities were conducted at the Leonard Wood Memorial Center for Leprosy Research (LWM) Skin \& Leprosy Clinic, a leprosy training facility in Cebu (Philippines) where this study was conducted. Training methodologies include the following:

(1) Lectures and orientation using a layman's local dialect. Patients were provided basic information about leprosy including the cause, manifestations and risks associated with reactions.

(2) Clinical pictures of skin lesions with or without reaction were shown. Then actual patients with or without lepra reaction were demonstrated.

(3) Closely supervised hands-on tool application using actual skin lesions of leprosy patients with or without reaction was conducted. Examples of mild, moderate and severe manifestations of skin reaction were demonstrated using clinical slides and actual patients.

(4) Proper identification and scaling of non-inflamed and inflamed skin lesions taken 3 successive times was required to satisfactorily complete the training.

Depending on educational background, it took 1-3 sessions lasting 45-60 min/session for the patients to complete the training and master the skill required. This was in addition to an initial 15-min lecture and orientation before patients were dispersed for individual training sessions.

\section{PRECAUTIONARY MEASURES}

Precautions were taken to avoid untoward incidents in case patients failed to identify inflamed lesions:

(1) Only patients adequately trained to identify and scale inflamed skin lesions were included.

(2) Monthly clinic visits were made mandatory.

(3) A 24/7 patient helpline for offsite consultation and monitoring was maintained. A mobile phone manned by experienced health staff was dedicated for this purpose.

(4) Other virtual platforms (e.g. a facebook page) for offsite consultations and referrals were created. 
(5) A well-trained field-surveillance team equipped with a field vehicle (mobile clinic) was dedicated for home visits of patients who missed their clinic visits and/or were at risk of deformities and other complications.

\section{STATISTICAL CALCULATIONS}

Power calculations were performed under the following assumptions: Each patient was expected to have an average of 3 skin lesions along the course of a peripheral nerve. For over $50 \%$ of the patients, these skin lesions would get inflamed during the observation period. ${ }^{1-4}$ By recruiting 200 patients, we expected to measure at least 300 nerves 'near' and 300 nerves 'distant' from inflamed skin lesions. Based on these assumptions, we would have $99 \%$ power to detect a difference between inflamed and non-inflamed skin lesions; and between nerves near and distant from inflamed vs non-inflamed skin lesions. Independent two-sample $T$ test, paired-sample $T$ test; and $P$ values were used as inferential stats to determine the difference between mean cohort values. Statistics analysis was done using Epi Info 7.

\section{ETHICAL APPROVAL}

Written approval of the Institutional Ethical Regulatory Committee was secured (IERC \#2017-01-001). Throughout the study, all clinical procedures were carried out in an ethical manner in accordance with guidelines of IERC and Good Medical Practice (GMP). An IERB reviewed and approved informed written consent was secured from each patient prior to study participation. For minor participants (below 18 years old), informed consent signed by both the patient and the parent/guardian was obtained.

\section{Results}

\section{CASE DEMOGRAPHICS}

Skin lesions and nerves were initially studied in 200 patients sequentially detected and monitored at the LWM Clinic. Among them, half, or 109 patients, 91\% of whom were MB cases, developed a reaction. These patients had their nerves and lesions evaluated, scored and compared before and during reaction. Among these cases, 314 inflamed skin lesions and nerve pairs were closely monitored and studied.

Demographically, the mean age of participants was 35 years and the male to female ratio was 2:1. Bacteriologically, at the start of the trial, $24 \%$ had low ABI $(<3)$; while $76 \%$ had high ABI $(\geq 3)$. Among the patients, $16 \%$ had only one lesion along the course of a nerve; $19 \%$ had two lesions; and $65 \%$ had three or more lesions located along the course of a nerve.

As to educational background, $10 \%$ were highly educated (college level); $85 \%$ were moderately educated (high school); and 5\% were less educated (primary level). All patients belonged to the lower socio-economic status.

\section{CLINICAL PROFILE OF INFLAMED SKIN LESIONS}

Among 600 skin lesions initially monitored, 314 became inflamed. Of those inflamed, 56\% (175) were type-1 and 44\% (139) were type-2. Inflamed skin lesions were closely monitored together with their nerve pairs (distant vs near) of which the functional status were compared relevant to their proximity to the skin lesions (see Tables 1-6). 
Table 1. Nerve and skin manifestations during reaction (N: 314). During reaction, the earliest and most common skin manifestations were swelling and redness; while most common nerve findings were sensory and motor impairment, mostly mild

\begin{tabular}{lccccc}
\hline Skin findings & No. & Percent & Nerve findings & No. & Percent \\
\hline Swelling & 261 & $83 \%$ & Sensory & 107 & $34 \%$ \\
Erythema & 167 & $53 \%$ & Motor & 105 & $33 \%$ \\
Tenderness & 108 & $34 \%$ & Enlargement & 58 & $18 \%$ \\
Fissures/Ulcer & 92 & $29 \%$ & Tenderness & 56 & $18 \%$ \\
& & & Pain & 54 & $17 \%$ \\
\hline
\end{tabular}

Table 2. Increase in skin lesion and nerve scores during reaction. There was a corresponding increase in both skin lesion and nerve scores during reaction. Clinical scores were more pronounced in type-1 compared to type-2 reaction $(P<0.0001)$

\begin{tabular}{|c|c|c|c|}
\hline Parameter & Before reaction $\mathrm{N}: 314$ & During reaction N: 314 & Remarks \\
\hline $\begin{array}{l}\text { Lesion score: Mean } \\
(95 \% \mathrm{CI}) \\
\operatorname{Max}\end{array}$ & $\begin{array}{c}1.94 \\
(1.94 \pm 0.10) \\
6\end{array}$ & $\begin{array}{c}4.99 * \\
(4.99 \pm 0.28) \\
15\end{array}$ & $\begin{array}{c}P<0.0001 \\
T \text { value }=32.3\end{array}$ \\
\hline $\begin{array}{l}\text { Nerve Score: Mean } \\
(95 \% \text { CI }) \\
\text { Max }\end{array}$ & $\begin{array}{c}0.24 \\
(0.24 \pm 0.07) \\
3\end{array}$ & $\begin{array}{c}1.03 * * \\
(1.03 \pm 0.15) \\
6\end{array}$ & $\begin{array}{c}P<0.0001 \\
T \text { value }=14.9\end{array}$ \\
\hline \multicolumn{4}{|c|}{$\begin{array}{l}\text { Mean lesion score was } 5.1 \text { for type- } 1 \text { vs } 4.8 \text { for type- } 2 \text { reaction }(P<0.0001),{ }^{* *} \text { Mean nerve score was } 1.1 \mathrm{fo} \\
\text { type-1 vs } 0.9 \text { for type-2 reaction }(P<0.0001) \text {. }\end{array}$} \\
\hline \multicolumn{4}{|c|}{$\begin{array}{l}\text { Table 3. Nerve abnormalities before and during reaction. A subset of cases (15\%) had pre-existing nerve } \\
\text { abnormalities preceding skin reaction while the rest of nerve abnormalities coexisted with skin reaction }\end{array}$} \\
\hline \multirow[t]{2}{*}{ Nerves near inflamed lesion } & \multicolumn{3}{|c|}{ Rate of nerve abnormalities } \\
\hline & Before skin reaction & Start of skin reaction & Peak of skin reaction \\
\hline $\begin{array}{l}\text { Total }=314 \\
(\text { Type- } 1=175) \\
\text { (Type- } 2=139)\end{array}$ & $\begin{array}{l}15.3 \% \\
(8.6) \\
(6.7)\end{array}$ & $\begin{array}{c}24.2 \% \\
(14.9) \\
(9.3)\end{array}$ & $\begin{array}{l}47.0 \% \\
(27.7) \\
(19.3)\end{array}$ \\
\hline
\end{tabular}

Table 4. Nerve proximity to inflamed lesions as risk factor of nerve abnormality. Nerve scores remained low in the absence of a reaction, and when a reaction occurred in the skin lesion 'distant' from the nerves. However, nerve scores were significantly higher when a skin lesion 'near' the nerve became inflamed $(P<0.0001)$

\begin{tabular}{lccc}
\hline Nerves & \multicolumn{3}{l}{ Nerve scores } \\
\cline { 2 - 4 } & Before reaction & During reaction & \\
\hline Distant from lesion mean score & 0.003 & 0.05 & $P<0.0001 ;$ \\
$(95 \%$ CI $)$ & $(0.003 \pm 0.006)$ & $(0.05 \pm 0.02)$ & $T$ value $=4.1$ \\
Near the lesion mean score & 0.24 & 1.03 & $P<0.0001 ;$ \\
$(95 \%$ CI $)$ & $(0.24 \pm 0.07)$ & $(1.03 \pm 0.15)$ & $T$ value $=14.9$ \\
$P$ value & $P=<0.0001$ & $P=<0.0001$ & \\
$T$ test & $T$ value $=6.60$ & $T$ value $=12.6$ & \\
\hline
\end{tabular}


Table 5. Clinical Scores of 6 Peripheral Nerves. Among the six peripheral nerves, although ulnar nerve had the highest nerve score $(95 \% \mathrm{CI}: 1.7+0.48)$, skin lesions located along the course of the posterior tibial nerve had the highest severity score (mean: 5.5) and highest proportion with associated visible deformities (5 of 54 or $9 \%$ )

\begin{tabular}{|c|c|c|c|c|c|}
\hline \multirow[t]{2}{*}{ Nerves near inflamed lesions } & \multirow[t]{2}{*}{ No } & \multirow{2}{*}{$\begin{array}{l}\text { Lesion score* } \\
\text { Mean }\end{array}$} & \multicolumn{2}{|c|}{ Nerve score } & \multirow[t]{2}{*}{ G2Ds } \\
\hline & & & Mean & $95 \%$ CI Max & \\
\hline Ulnar & 55 & 5.2 & 1.7 & $1.7 \pm 0.487$ & None \\
\hline C Peroneal & 56 & 5.2 & 1.1 & $1.1 \pm 0.395$ & None \\
\hline Post tibial & 54 & 5.5 & 1.0 & $1.0 \pm 0.366$ & P. ulcer: 5 cases \\
\hline Radial & 59 & 4.9 & 0.9 & $0.9 \pm 0.264$ & None \\
\hline Facial & 49 & 4.9 & 0.8 & $0.8 \pm 0.293$ & Lagoph: 2 cases \\
\hline Median & 41 & 4.1 & 0.7 & $0.7 \pm 0.263$ & None \\
\hline Total & 314 & & & & \\
\hline
\end{tabular}

* Lesion score refers to the score of the lesion near or running along the course of the nerve.

Table 6. Deformities $(n=7)$. At peak of reaction, seven G2Ds were recorded. All 7 nerves associated with visible deformities were located 'near' inflamed skin lesions. None of the nerves located 'distant' from inflamed skin lesions was associated with visible deformities. Due to prompt referral and intervention, better clinical outcomes were attained. All cases who developed deformities had a lesion and nerve score of $>3$

\begin{tabular}{lccccccc}
\hline Deformity & $\begin{array}{c}\text { Nerve distance to } \\
\text { lesion }\end{array}$ & $\begin{array}{c}\text { Rxn } \\
\text { type }\end{array}$ & $\begin{array}{c}\text { Lesion } \\
\text { score }\end{array}$ & $\begin{array}{c}\text { Nerve } \\
\text { score }\end{array}$ & $\begin{array}{c}\text { Clinical outcome of } \\
\text { G2D (post-steroid tx) }\end{array}$ & $\begin{array}{c}\text { Lep } \\
\text { type }\end{array}$ & Remarks \\
\hline Lagophthalmos & Near & 1 & 8 & 3 & Full recovery & MB & All \\
Lagophthalmos & Near & 1 & 7 & 3 & Partial recovery (90\%) & MB & A \\
Plantar ulcer & Near & 2 & 3 & 3 & Full recovery & MB & G2Ds \\
Plantar ulcer & Near & 2 & 7 & 3 & Full recovery & MB & occured \\
Plantar ulcer & Near & 2 & 3 & 3 & Full recovery & MB & during \\
Plantar ulcer & Near & 2 & 15 & 6 & Full recovery & MB & MDT \\
Plantar ulcer & Near & 1 & 6 & 4 & Full recovery & MB & \\
\hline
\end{tabular}

* Clinical Outcome $=90 \%-100 \%$ improvement was achieved; with lesion scores back to a maximum of 2 and nerve scores to a maximum of 1 . Mean time to referral and intervention was 2 weeks.

ROLE OF GENDER AND EDUCATIONAL STATUS ON PATIENTS' ABILITY TO SELF-EVALUATE SKIN LESIONS

During the study, based on gender and educational background, there was no significant difference in the patients' ability to recognize and scale the lesions. This was attributed to prior training and translation of the clinical tool into a layman's local dialect.

However, during training, a slight difference was observed. It took longer for less educated patients to complete the training. However, as training progressed and self -evaluation became repetitive, patients gradually mastered the skill to recognize and scale inflamed skin lesions so that during the study, all participants could comparably and reliably be delegated to selfevaluate their skin lesions, regardless of educational background.

\section{FEASIBILITY, ACCEPTABILITY AND PATIENT RELIABILITY}

The use of the self-assessment tool was feasible and highly acceptable among patients. Most patients considered the tool highly acceptable (user-friendly), important and beneficial (Yes, a lot $=95 \%$; Yes, a little $=5 \%$ ). These findings were maintained through study completion.

Furthermore, our findings suggest that with proper orientation and training, patients can reliably be delegated to evaluate their own lesions.In this study, patient score readings were 
Table 7. Concordance of clinician and patients' lesion severity readings. The patient's skin lesion severity assessment was comparable with that of the clinician both at baseline and during reaction (95\% CI: $4.99+0.28$ vs $5.14+0.23 ; P=0.177)$

\begin{tabular}{lccccc}
\hline & \multicolumn{2}{c}{ Before reaction } & & \multicolumn{2}{c}{ During reaction } \\
\cline { 2 - 3 } \cline { 5 - 6 } Evaluator & \multicolumn{2}{c}{ Lesion scores } & & \multicolumn{2}{c}{ Lesion scores } \\
\hline & Mean $95 \% \mathrm{CI}$ & & & Mean $95 \%$ \\
Clinician & $1.85(1.85 \pm 0.08)$ & $P=0.177$ & & $5.14(5.14 \pm 0.23)$ & $P=0.177$ \\
Patient & $1.94(1.94 \pm 0.10)$ & $T$ value $=1.34$ & & $4.99(4.99 \pm 0.28)$ & $T$ value $=1.35$ \\
\hline
\end{tabular}

comparable with that of the clinician as shown in Table 7. Likewise, using an LSI 5-point score interval for mild, moderate and severe manifestations, its concordance with physician's global assessment on lesion severity was $95.4 \%$.

\section{BACTERIOLOGIC INDEX}

Severity of skin and nerve findings showed no significant difference between high BI and low BI cases (lesion Scores $=95 \%$ CI: $4.94 \pm 0.42$ vs $5.01 \pm 0.35 ; P=0.83$ ) (nerve Scores $=95 \%$ CI $0.88 \pm 0.29$ vs $1.09 \pm 0.17 ; P=0.23)$.

\section{STEROID TREATMENT}

To reduce the likelihood of masking a possible neuritis, skin reactions without nerve impairment were not treated with steroids unless for ethical reasons, skin lesions worsened by at least $20 \%$ resulting in personal or social dysfunction; or if skin lesions were accompanied by persistent nerve or systemic signs and symptoms beyond one week of supportive medication. However, severe neuritis with or without skin reaction were immediately treated with steroids. Based on these treatment criteria, 15 were treated with steroids due to neuritis and the rest due to worsening of skin and systemic manifestations unresponsive to palliative treatment. All cases combined, a total 58 of 109 patients with lepra reaction qualified for steroid medication and clinically improved. These patients represented 171 of 314 inflamed lesions included in the study.

In all instances however, steroids were only initiated after full dermatologic and neurologic assessment were performed and clinical scores were recorded for analyses.

\section{THE PATIENT HELPLINE}

Forty-five patients used the mobile phone patient helpline, mostly for their lepra reactions, while a few used it for counseling and clinic appointment. The average number of calls by these 45 patients was five during the course of the study. Due to work, geographic and resource limitation, the helpline was very important in facilitating prompt referral and timely intervention of adverse events resulting in better treatment and clinical outcomes.

\section{Discussion}

FEASIBILITY, ACCEPTABILITY, PATIENT RELIABILITY

Most patients considered the tool highly acceptable (user-friendly), important and beneficial. These findings were maintained through study completion. The tool was introduced to the patients with ease, without logistic or ethical issues.Furthermore, our findings suggest that 
with proper orientation and training, patients can reliably be delegated to evaluate their own skin lesions. In this study, patient's skin lesion severity assessment was comparable with that of the clinician. Furthermore, using an LSI 5-point score interval for mild, moderate and severe manifestations, its concordance with the physician's global assessment on lesion severity was $95.4 \%$.

These findings are very encouraging because it would mean that the self-monitoring tool could easily be introduced to our target end-users; and would likely improve a patient's healthseeking behavior since they will be trained, empowered and actively involved in the monitoring of their own skin lesions.

\section{CLINICAL SCORES AND OBSERVATIONS DURING REACTION}

During reaction, there was a corresponding increase in both skin lesion and nerve scores particularly at peak of reaction. The mean skin lesion score was 1.94 in the absence of a reaction (95\% CI: 1.84-2.04); and 4.99 at peak of reaction (95\% CI: 4.71-5.27). In this cohort, the earliest and most common skin signs of reaction were swelling and redness of previously pale and flat lesions. These findings underscore the importance of heightened vigilance over these early, easy to detect skin manifestations of reaction which require prompt referral.

\section{IMPORTANCE OF CLOSE MONITORING OF NERVES UNDERNEATH SKIN LESIONS}

Although this study underscores the importance of close monitoring of nerves near or underneath 'inflamed' lesions, regular monitoring of nerves near or underneath 'non-inflamed' lesions also need attention. This was supported by our observation in $15 \%$ of cases with nerve findings preceding skin reaction. These abnormalities could have silently progressed to nerve damage and gross deformities without visible skin signs of an incipient nerve damage underneath.

\section{DEFORMITIES ASSOCIATED WITH NERVES NEAR/BENEATH INFLAMED LESIONS}

There were seven visible deformities recorded, 2 cases of lagophthalmos and 5 of plantar ulcer. Nerves involved were located near or underneath inflamed skin lesions. However, due to prompt self-referral, deformities were detected and reported early, were clinically mild and were resolved or significantly improved within a few weeks of prompt medical intervention. The mean time from onset to referral for medical intervention was 2 weeks.

Onset of visible deformities was observed at the peak of reaction with nerve scores $\geq 3$ (max: 6 ) and lesion scores $\geq 3$ (max: 15 ). Due to prompt referral however, timely intervention was initiated. This resulted in better treatment outcomes with $90 \%-100 \%$ clinical improvement as lesion scores reduced to a maximum of 2 and nerve scores to a maximum of 1 .

In contrast, no deformity associated with nerves distant from inflamed lesions was reported.

\section{RATE OF DEFORMITIES INCREASED AS LESION SCORES INCREASED}

Among 314 skin lesions, 50 had a lesion score $<3$ and none developed deformity; while 264 had a lesion score $\geq 3$ and 7 (2.7\%) developed gross deformities. The rate of deformities increased as skin lesion scores increased. Although clinical scores were significantly higher in type-1 reaction, the rate of deformities was higher in type-2 reaction (1.7\% vs $2.9 \%$ ). 
It is also noteworthy that among six nerves reviewed, the posterior tibial nerve got the highest lesion score which corresponds to its high rate of deformities ( 5 of 54 or 9\%). This further supports our hypothesis in the utility of inflamed lesions as proxy indicator of nerve abnormalities in leprosy.

NERVE PROXIMITY TO INFLAMED LESIONS AS RISK FACTOR OF NERVE ABNORMALITY AND DEFORMITY

Our findings suggest that the clinical score at risk of deformity is $\geq 3$, particularly if skin lesions near or along the course of a nerve were inflamed.

In this study, nerve scores remained low in the absence of a reaction, and when a reaction occurred in the lesion 'distant' from the nerve (95\% CI: $0.05 \pm 0.02)$. However, nerve score was significantly higher when the skin lesion 'near' the nerve became inflamed (95\% CI: 1.03 $\pm 0.15) ;(P=<0.0001 ; T=12.6)$. These findings suggest higher risk of abnormalities among nerves located near or underneath inflamed skin lesions.

RELEVANCE AND FIELD APPLICABILITY OF THE SELF-MONITORING TOOL

Findings in this study will hopefully guide our health workers in maximizing their limited resources by streamlining their case priorities among patients at risk-that is, patients with inflamed skin lesions along the course of a nerve may need more attention than the rest of the patient population. For instance, in a cohort of 100 patients, the clinician has now the option of safely delegating the monitoring of 80 low risk cases so that the 20 high risk cases can be more efficiently be closely monitored. This targeted streamlined approach, combined with patient inclusion and empowerment is crucial in the timely referral of reactions so that timely intervention is initiated and deformity prevented.

Correspondingly, the use of the 'self-assessment' tool could promote patient inclusion and improve a patient's health-seeking behavior through greater involvement and empowerment to monitor his lesions.

\section{WEAKNESSES OF THE STUDY}

This acceptability and feasibility study used clinical tools which are not yet validated. Moreover, since the lesion monitoring tool is intended for patient use, it is generic and nonspecific by reaction type. However, since study outcomes are encouraging, a tool validation study is planned.

\section{Conclusions and recommendations}

This study demonstrates the feasibility and patient acceptability of a skin lesion selfassessment tool and that our patients can reliably be delegated to evaluate their own skin lesions resulting in prompt referral and timely intervention. Furthermore, our findings demonstrate the potential role of an inflamed skin lesion as proxy indicator of nerve abnormality; and the higher risk of abnormalities among nerves near inflamed skin lesions.

Likewise, it would be helpful to evaluate the tool's field applicability and acceptability among health workers and broadly translate positive findings into routine practice through collaborative efforts with field partners. Further studies in the feasibility and cost-efficiency of translating the tool into an app-assisted system for offsite consults and referrals is recommended.

Furthermore, since study outcomes are promising, a tool validation study is recommended. 


\section{Acknowledgements}

We wish to thank the Leprosy Research Initiative (LRI) for the guidance and funding support; our LWM staff particularly Junie Abellana, Tonet Taborada and Riza Sanchez for their contribution to the study. We also wish to thank our patients for their diligence and commitment through study completion; most especially to God for the opportunity to serve through this project.

\section{Conflict of interest}

PS is the Editor of Leprosy Review: he was not involved with any part of the review or decision process for this article. The authors declare no other conflict of interest, neither financial nor non-financial, which could influence the role they may play in the outcome and publication of the paper.

\section{Funding}

The authors declare independence from the funder of this project, the Leprosy Research Initiative (LRI). This project was funded under LRI funding grant \#705.17.07.

\section{References}

1 Balagon M, Gelber R, Abalos R, Cellona R. Reactions following completion of 1 and 2 year multiple drug therapy (MDT). Am J Trop Med Hyg, 2010; 83(3): 637-644. https://doi.org/10.4269/ajtmh.2010.09-0586.

2 Walker SL, Balagon MF, Darlong J, Doni SN, Hagge DA, Halwai V, John A, Lambert SM, Maghanoy AA, Nery JC, Neupane KD, Nicholls PG, Pai VV, Parajuli P, Sales AM, Sarno E, Shah M, Tsegaye D, Lockwood DJ. ENLIST 1: an international multi-centre cross-sectional study of the clinical features of erythema nodosum leprosum. PLoS Negl Trop Dis, 9(9): e0004065. Epub Sep 2015.

3 Balagon MF, Gelber RH, Abalos RM, Cellona RV. Lepra reactions after multidrug therapy for multibacillary (MB) leprosy. Int J Lepr Rev, 2005; 73(4): 302.

4 Ravanes J, Cellona R, Balagon M, Abalos R, Walsh G, Walsh D. Longitudinal ocular survey of 202 Filipino patients with multibacillary (MB) leprosy treated with 2 year WHO-multiple drug therapy. Southeast Asian $J$ Trop Med Public Health, 2011; 42(2): 323-330.

5 Hogeweg M, Kiran K, Suneetha S. The significance of facial patches and type 1 reaction for the development of facial nerve damage in leprosy. A retrospective study among 226 paucibacillary leprosy patients. Lepr Rev, 1991; 62: 143-149. https://doi.org/10.5935/0305-7518.19910016.

6 Kiran K, Stanley J, Pearson J. The outpatient treatment of nerve damage in patients with borderline leprosy, using a semi-standardized steroid regimen. Lepr Rev, 1985; 56: 127-340. https://doi.org/10.5935/0305-7518.19 850016.

7 Touw-Langendijk M, Brandsma J, Andrew J. Treatment of ulnar and median nerve loss in borderline leprosy. Lepr Rev, 1984; 55: 41-46. https://doi.org/10.5935/0305-7518.19840005.

8 Scheelbeek P, Balagon M, Orcullo F, Maghanoy A, Abellana J, Saunderson P. A retrospective study of the epidemiology of leprosy in Cebu: an eleven-year profile. PLoS Negl Trop Dis, 2013; 7(9): e24444. https://doi.or g/10.1371/journal.pntd.0002444.

9 Balagon MF, Cellona RV, Fajardo TT Jr, Villahermosa LG, Abalos RM, Tan EV, Walsh DS, DelaCruz EC, Walsh GP. Detection of new leprosy cases at a walk-in skin clinic in Cebu City, Philippines highlights surveillance. Int $J$ Dermatol, 1998; 38: 796-800. 
Appendix A. Assessment tools

Table A1. Skin lesion self-monitoring tool (skin lesion severity index; LSI) total score: 0-15

\begin{tabular}{|c|c|c|c|c|c|}
\hline $\begin{array}{l}\text { Lesion } \\
\text { score }\end{array}$ & $\begin{array}{l}\text { Score } \\
(0-3)\end{array}$ & 0 & 1 & 2 & 3 \\
\hline Size & & $\begin{array}{l}\text { Very small } \\
(\leq 25 \mathrm{~mm})\end{array}$ & $\begin{array}{l}\text { Small } \\
(>25-50 \mathrm{~mm})\end{array}$ & $\begin{array}{l}\text { Average } \\
(>50-75 \mathrm{~mm})\end{array}$ & Large (>75 mm) \\
\hline Surface & & $\begin{array}{l}\text { No fissure/skin } \\
\text { break }\end{array}$ & $\begin{array}{l}\text { Mild fissure/skin } \\
\text { break }\end{array}$ & $\begin{array}{l}\text { Moderate } \\
\text { fissure/skin break }\end{array}$ & $\begin{array}{l}\text { Severe fissure/skin } \\
\text { break; ulceration }\end{array}$ \\
\hline Color & & $\begin{array}{l}\text { Whitish, pale or } \\
\text { brown }\end{array}$ & Pinkish & Light red & Dark red; very red \\
\hline $\begin{array}{l}\text { Swelling } \\
\text { (Edema) }\end{array}$ & & No swelling & Slight swelling & $\begin{array}{l}\text { Moderate } \\
\text { swelling }\end{array}$ & $\begin{array}{l}\text { Significant } \\
\text { swelling }\end{array}$ \\
\hline Tenderness & & $\begin{array}{l}\text { Non-tender/no } \\
\text { discomfort }\end{array}$ & $\begin{array}{l}\text { Slight tender- } \\
\text { ness/discomfort }\end{array}$ & $\begin{array}{l}\text { Moderate tender- } \\
\text { ness/discomfort }\end{array}$ & $\begin{array}{l}\text { Very tender/un- } \\
\text { comfortable; } \\
\text { patient withdraws } \\
\text { from light touch }\end{array}$ \\
\hline
\end{tabular}

Table A2. Nerve evaluation (Nerve severity index; NSI) total score: 0-15

\begin{tabular}{|c|c|c|c|c|c|}
\hline Nerve score & $\begin{array}{l}\text { Score } \\
(0-3)\end{array}$ & 0 & 1 & 2 & 3 \\
\hline Nerve size & & Normal & Slightly enlarged & $\begin{array}{l}\text { Moderately } \\
\text { enlarged }\end{array}$ & $\begin{array}{l}\text { Significantly } \\
\text { enlarged }\end{array}$ \\
\hline $\begin{array}{l}\text { Nerve } \\
\text { tenderness }\end{array}$ & & Non-tender & $\begin{array}{l}\text { Slightly tender; } \\
\text { tender on deep } \\
\text { palpation }\end{array}$ & $\begin{array}{l}\text { Moderately } \\
\text { tender; tender on } \\
\text { light palpation }\end{array}$ & $\begin{array}{l}\text { Significantly tender; } \\
\text { patient withdraws } \\
\text { from light palpation } \\
\text { or touch }\end{array}$ \\
\hline Nerve Pain & & No pain & $\begin{array}{l}\text { Pain during } \\
\text { activities }\end{array}$ & Pain at rest & Pain disturbs sleep \\
\hline Sensory & & Normal & Misreference & Hyposthetic & Anesthetic \\
\hline $\begin{array}{l}\text { Motor } \\
\text { function }\end{array}$ & & $\begin{array}{l}\text { Full movement } \\
\text { with strong } \\
\text { resistance }\end{array}$ & $\begin{array}{l}\text { Full movement } \\
\text { with slight } \\
\text { resistance }\end{array}$ & $\begin{array}{l}\text { Weak; full or } \\
\text { incomplete } \\
\text { movement with } \\
\text { no resistance }\end{array}$ & $\begin{array}{l}\text { No movement or } \\
\text { paralysis }\end{array}$ \\
\hline Total score & & & & & \\
\hline
\end{tabular}

